\title{
Heterogeneous electro-Fenton treatment: preparation, characterization and performance in groundwater pesticide removal
}

\author{
O. Iglesias ${ }^{\text {a }}$, M.A. Fernández de Dios ${ }^{\text {a }}$, T. Tavares ${ }^{\text {b }}$, M.A. Sanromán ${ }^{\text {a }}$, M. Pazos ${ }^{a, *}$ \\ a Department of Chemical Engineering, University of Vigo, Isaac Newton Building, Campus As Lagoas, Marcosende 36310, Vigo, Spain \\ ${ }^{\mathrm{b}}$ Department of Biological Engineering, University of Minho, Braga, 4710-057, Portugal
}

\section{A R T I C L E I N F O}

\section{Article history:}

Received 8 February 2014

Received in revised form 2 October 2014

Accepted 31 December 2014

Available online 9 January 2015

\section{Keywords:}

Pump and treat

Imidacloprid

Chlorpyrifos

Electro-Fenton

Y zeolite

Fe catalyst

\begin{abstract}
A B S T R A C T
In this work the preparation, characterization and performance of Y-zeolite as catalyst for electro-Fenton treatment of pesticides was carried out. Initially iron supported Y-zeolite (Fe-Y) was prepared and evaluated for the degradation of imidacloprid and chlorpyrifos. Kinetic studies determined that the pesticides removal followed a pseudo-first-order kinetic model. However, the reusability of this catalyst was not appropriated and to enhance its recyclability, Fe-Y catalyst was embedded in alginate (Al-Fe-Y). The new catalyst showed similar degradation efficiency; and the recyclability was improved. This study demonstrated that Al-Fe-Y could be efficiently used to remove commonly pesticides, imidacloprid and chlorpyrifos, from aqueous medium.
\end{abstract}

(c) 2015 The Korean Society of Industrial and Engineering Chemistry. Published by Elsevier B.V. All rights reserved

\section{Introduction}

Groundwater pollution is very difficult to mitigate due to the high residence time, the hard access and the ease of spreading long distances. A common approach for managing polluted groundwater is to remove or contain contaminant sources and to address down-gradient contamination using pump-and-treat (P\&T) technology [1]. This technology is a classic ex-situ treatment which consists in two stages: pumping, where the polluted plume is extracted by pumping wells; and treatment, in which the pollutants are removed from the extracted water. The water treatment can be performed using mechanical, physical, biological, and chemical methods. However, it is necessary to take into account two main factors, the high amount of water to be treated and the nature of the pollution, in order to achieve an effective treatment.

The appearance of newly emerging organic contaminants is increasing in the groundwater [2]. These pollutants penetrate into the water body due to the runoff from urban areas, return flows from agricultural fields and leaching [3,4]; furthermore, they are

\footnotetext{
* Corresponding author. Tel.: +34 986 818723; fax: +34 986812380 .

E-mail addresses: olaiaic@uvigo.es (O. Iglesias), mafdedios@uvigo.es (M.A. Fernández de Dios), ttavares@deb.uminho.pt (T. Tavares), sanroman@uvigo.es (M.A. Sanromán), mcurras@uvigo.es (M. Pazos).
}

difficult to treat using conventional treatment technologies. Therefore, different approaches are being explored to accomplish an appropriated treatment of these pollutants [4-9]. Recently, the electro-Fenton process has attracted great interest from the scientific community because this treatment can be used to remove a wide variety of organic pollutants, including pesticides $[10,11]$. This technology combines the classical Fenton treatment with the electrochemical oxidation. Thus, the electrical current induces the in situ generation of $\mathrm{H}_{2} \mathrm{O}_{2}$ via reduction of oxygen, and the catalytic reaction is propagated by $\mathrm{Fe}^{2+}$ regeneration, which can take place by reduction of $\mathrm{Fe}^{3+}$ with $\mathrm{H}_{2} \mathrm{O}_{2}$, hydroperoxyl radical, organic radical intermediates, or directly at the cathode.

In order to couple this process to the P\&T technology, it is necessary to design a system that can operate in continuous mode. In this context, the electro-Fenton treatment using heterogeneous catalyst arises. The iron immobilization onto a support provides a physical retention of the catalyst avoiding the iron release in the treated water. For this reason, this specific field attracted the attention of scientific researches worldwide [12-15]. In the last years, our research group has invested great efforts in the design of electro-Fenton reactors as well as developed several catalysts, iron alginate gel beads and iron-sepiolite, for heterogeneous Fenton and electro-Fenton degradation of dyes [11,16-19]. From these previous studies, it was determined that inorganic supports, such as clays, were adequate to perform heterogeneous catalyst. 
Zeolite is a well-known low-cost material widely used for metal removal [20,21] and in recent times, the scientific community increased its attention to use it as catalyst support. Fukuchi et al. [22] used iron-supported natural zeolite for the degradation of 2,4,6-tribromophenol in a heterogeneous Fentonlike system and Kiran et al. [23] utilized iron-modified zeolite catalyst for photocatalytic Fenton oxidation of sodium dodecyl sulfate. However, we could not find information about testing, iron supported zeolite as catalyst for the electro-Fenton treatment of pesticides. Therefore, the aim of this work is the development of a new electro-Fenton process using iron supported zeolite (Fe-Y) to treat pesticides typically present in groundwater. In this case, a Y-type zeolite, NaY, was selected due to its stable structure, large pore volume and cation exchange capacity; the presence of aluminum ions in the framework results in negative charges that are balanced with cations [24]. Initially the preparation and characterization of $\mathrm{Fe}-\mathrm{Y}$ was performed and then the developed catalyst was tested for the electro-Fenton degradation of two model pesticides of different nature, imidacloprid and chlorpyrifos.

\section{Material and Methods}

\section{Materials}

Zeolite NaY supplied by Sigma-Aldrich (Barcelona, Spain) was evaluated as support for the catalyst.

Pesticide solutions were prepared using pesticide-grade Pestanal analytical standard provided by Sigma-Aldrich (Barcelona, Spain) at a desired concentration (Table 1).

Iron stock solution was obtained by dissolving $\mathrm{Fe}_{2}\left(\mathrm{SO}_{4}\right)_{3} \cdot \mathrm{nH}_{2} \mathrm{O}$ (Sigma-Aldrich, Barcelona, Spain) in deionized water, each desired concentration was obtained by diluting this stock solution.

$\mathrm{Na}$-alginate and $\mathrm{CaCl}_{2}$ were analytical grade and supplied by Sigma-Aldrich (Barcelona, Spain).

\section{Zeolite acid pre-treatment}

Acid pre-treatment of Y zeolite was performed following Pazos et al. [25]. A suspension of zeolite and $0.1 \mathrm{M} \mathrm{H}_{2} \mathrm{SO}_{4}$ (ratio $1: 10 \mathrm{~g}: \mathrm{mL})$ was maintained in agitation $(150 \mathrm{ppm})$ at $25^{\circ} \mathrm{C}$ for 24 hours. After that, the suspension was filtered through filter paper and the zeolite was dried 24 hours in oven at $60^{\circ} \mathrm{C}$, separated from the paper and preserved.

\section{Adsorption assays}

Batch adsorption assays were carried out in $250 \mathrm{~mL}$ Erlenmeyer flasks by mixing $3 \mathrm{~g}$ of pre-treated Y zeolite with a constant volume $(150 \mathrm{~mL})$ of the iron aqueous solution at a desired concentration. The flasks were agitated in an incubator (Thermo Forma) at $150 \mathrm{rpm}$ and $20^{\circ} \mathrm{C}$. In order to analyse iron adsorption, samples were taken of the supernatant and were centrifuged (Sigma 3K-18) during $15 \mathrm{~min}$ at $5000 \mathrm{rpm}$ to remove solid. Atomic Absorption Spectroscopy (Agilent 240FS) was used to measure the iron that remained unsorbed in the supernatant liquid.

Iron uptake (q) concentration was determined by the following equation:

$\mathrm{q}=\left(A_{i}-A_{f}\right) / m$

Where $A_{i}$ is the initial amount of iron in solution ( $\mathrm{mg}$ ), $A_{f}$ is the final amount of iron in solution ( $\mathrm{mg}$ ) and $m$ is the mass of utilized $\mathrm{Y}$ zeolite $(\mathrm{g})$.

All the adsorption studies were repeated three times; the reported value is the average of measurements, the experimental error was calculated as the standard deviation, which was below $3 \%$ in all cases.

\section{Catalyst preparation}

The Fe-Y obtained from the adsorption assays, at a concentration of $52.21 \mathrm{mg} \mathrm{g}^{-1}$, was directly used as catalyst and was also tested embedded in alginate gel. For the later, a suspension of $\mathrm{Na}-$ alginate (3\%) containing Fe-Y was dropped on a solution of $0.2 \mathrm{M}$ $\mathrm{CaCl}_{2}$ to create the spherical alginate beads with the Fe-Y zeolite entrapped into its structure.

\section{Characterization of catalyst}

Fourier-transform infrared (FT-IR) spectra of the $\mathrm{Y}$ zeolite and Fe-Y were recorded on an FT-IR spectrometer (model FT-IR/ 4100 , Jasco). The samples were ground into powder and dried in an oven at $60^{\circ} \mathrm{C}$ for $1 \mathrm{~h}$. The potassium bromide (KBr) pellet

Table 1

Type, CAS number, structure, solubility and concentration of studied pesticides.

\begin{tabular}{|c|c|c|c|c|c|}
\hline Pesticide & Type & CAS number & Structure & $\begin{array}{l}\text { Solubility water } \\
20^{\circ} \mathrm{C}\left(\mathrm{mg} \cdot \mathrm{L}^{-1}\right)\end{array}$ & $\begin{array}{l}\text { Concentration } \\
\left(\mathrm{mg} \cdot \mathrm{L}^{-1}\right)\end{array}$ \\
\hline $\begin{array}{l}\text { Imidacloprid } \\
\text { 1-(6-chloro-3-pyridyemethyl)- } \\
\text { N-nitroimidazolidine-2-yliedeneamine }\end{array}$ & $\begin{array}{l}\text { chloronicotinyl } \\
\text { nitroguanidine }\end{array}$ & $13826-41-3$ & & 610 & 100 \\
\hline $\begin{array}{l}\text { Chlorpiryfos } 0 \text {, O-diethyl } \\
\text { O-(3, 5, 6-trichloro-2-pyridyl)- } \\
\text { phosphorothioate }\end{array}$ & organophosphate & $2921-88-2$ & & 2 & 1.3 \\
\hline
\end{tabular}


press method was used to improve the signal in the infrared spectra.

In order to evaluate the morphological status of the developed catalysts Scanning Electron Microscopy and Energy Dispersive Spectrometry (SEM/EDS) were performed on a JEOL JSM-6700F equipped with an EDS Oxford Inca Energy 300 SEM using an accelerating voltage of $20 \mathrm{kV}$ (Electron Microscopy Service, C.A.C.T.I., University of Vigo).

\section{Batch electro-Fenton treatments}

Several batch experiments were done in an electro-Fenton cell reactor with a working volume of $0.15 \mathrm{~L}$ (Fig. 1) [11]. The reactor was filled with the catalyst and an aqueous solution of pesticide at a desired concentration. This solution was agitated with a magnetic stirred in order to avoid concentration gradients. For all experiments, the electrolyte utilized was $0.01 \mathrm{M} \mathrm{Na}_{2} \mathrm{SO}_{4}$. A cathode of graphite sheet (CARBON LORRAINE, France) and a Boron-Doped Diamond (BDD) (DIACHEM $\AA$, Germany) anode were connected to a power supply at a constant voltage of $5 \mathrm{~V}$ (HP model 3662 ) [26]. The electrodes (surface $11 \mathrm{~cm}^{2}$ ) were placed opposite to each other with an electrode gap of $6 \mathrm{~cm}$. A continuous bubbling $\left(1 \mathrm{~L} \mathrm{~min}^{-1}\right)$ of air at atmospheric pressure was located into the reactor on the cathode surroundings, this flow started 10 minutes before the electro-Fenton process in order to reach a stationary $\mathrm{O}_{2}$ concentration. This was carried out for the in situ generation of $\mathrm{H}_{2} \mathrm{O}_{2}$ by the electrochemical reduction of oxygen.

\section{Pesticide analysis}

Pesticide concentration in the samples was determined by means of HPLC (Agilent 1100) equipment with an XDF-C8 reversephase column ( $150 \times 4.6 \mathrm{~mm}$ i.d., $5 \mu \mathrm{m})$. Prior to injection, the samples were filtered through a $0.45 \mu \mathrm{m}$ Teflon filter. The injection volume was set at $20 \mu \mathrm{L}$, and the isocratic eluent (acetonitrile and water) was pumped at a rate of $1 \mathrm{~mL} \mathrm{~min}^{-1}$. Detection was

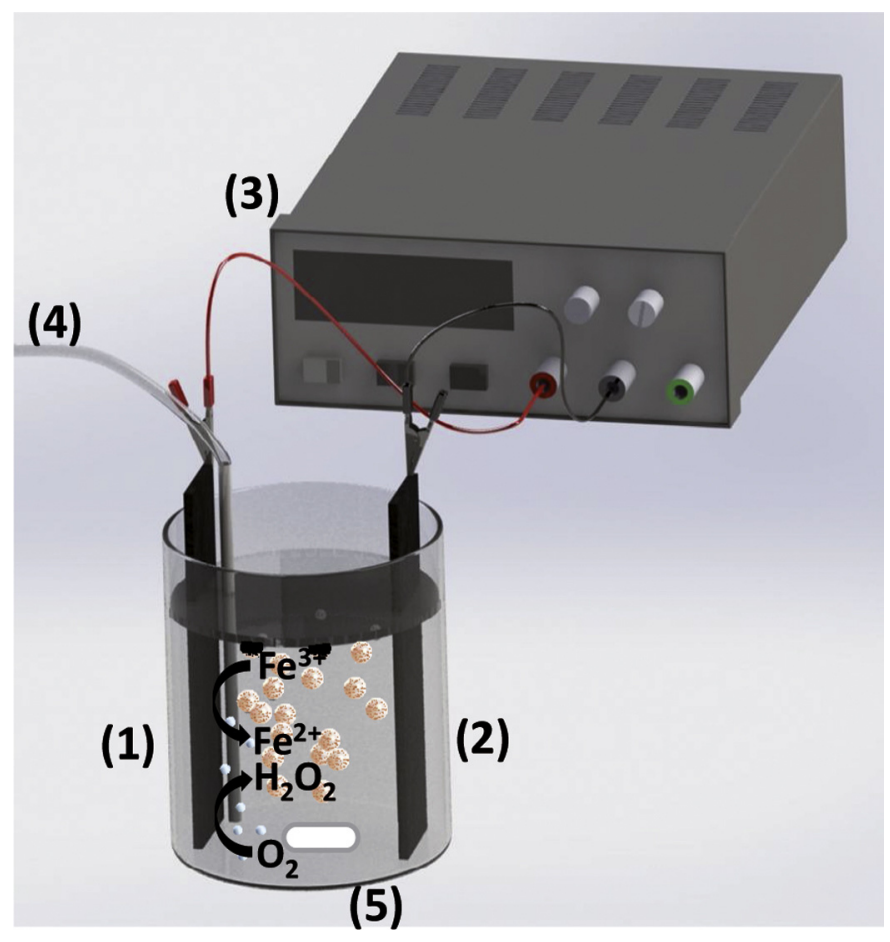

Fig. 1. Schematic diagram of electro-Fenton experimental setup in batch process: cathode (1), anode (2), power supply (3), air (4), magnetic stirrer (5). performed with a diode array detector at $270 \mathrm{~nm}$ for the imidacloprid measurement and $291 \mathrm{~nm}$ for chlorpyrifos, and the column temperature was maintained at room temperature.

In order to identify the transformation products obtained in the pesticide degradation several samples were analyzed with a HPLCMS (Agilent 1100) equipment with a LC column Luna 5u C18 100A. Filtration through a $0.45 \mu \mathrm{m}$ Teflon filter was done before the injection. In this case the isocratic eluent was 98\% (aqueous solution $1 \mathrm{nM}$ of sodium formiate and $0.1 \%$ of formic acid) and $2 \%$ (acetonitrile and a $0.1 \%$ of formic acid) that was pumped at a rate of $0.4 \mathrm{~mL} \mathrm{~min}^{-1}$ for 40 minutes. Detection was carried out with a diode array detector at $220 \mathrm{~nm}$ and the column temperature was maintained at $35^{\circ} \mathrm{C}$. The coupled mass spectrometer employed was a Hewlett-Packard 5989B with a detection range from 10 to 2000 Da.

\section{Measurement of process efficiency}

In addition to analyzing the pesticide concentration and therefore its removal during the experiments, other specific energetic parameters are useful. In this study the energy consumption per pesticide mass was evaluated following the equation:

Energy consumption $\left(\mathrm{kWh} / \mathrm{kg}_{\text {pesticide }}\right)=\frac{I \cdot V \cdot t}{\Delta \mathrm{m}_{\text {pesticide }}}$

where I is the average applied current (A), V is the cell voltage (V), $\mathrm{t}$ is the treatment time $(\mathrm{h})$ and $\Delta \mathrm{m}$ is the pesticide mass removed $(\mathrm{kg})$.

\section{Results and discussion}

In this study, the developments of new catalysts using Fe-Y and $\mathrm{Fe}-\mathrm{Y}$ embedded in alginate $(\mathrm{Al}-\mathrm{Fe}-\mathrm{Y})$ were described for their use in the electro-Fenton treatment. To evaluate the electro-Fenton process using the developed catalysts, two pesticides of different solubility, imidacloprid (high solubility) and chlorpyrifos (low solubility), were selected as representative pesticides in groundwater [27-29].

\section{Iron adsorption onto Y zeolite}

The first step for developing the electro-Fenton catalyst was to evaluate the adsorption capacity of the selected support. For that purpose, batch adsorption assays at different concentrations were accomplished using NaY zeolite. It was noticed that for the several $\mathrm{Fe}(\mathrm{III})$ tested concentrations, ranged from $50-1000 \mathrm{mg} \mathrm{L}^{-1}$, no iron was detected in the liquid medium after adsorption. In these experiments, the colour of the zeolite changed from white to red brown and the $\mathrm{pH}$ in the liquid medium increased up a value around 5. This fact is in accordance with several authors that have reported that zeolites can increase the $\mathrm{pH}$ in their surroundings $[25,30]$. Therefore, it was assumed that this change of colour was due to the iron precipitation as hydroxide or oxide. Hence, zeolite was pre-treated with acid to assure a proper iron adsorption in the zeolite and to avoid the iron precipitation on the zeolite surface due to the high pH in the medium [25]. In Fig. 2, the iron adsorptions and the $\mathrm{pH}$ in the suspensions, using untreated and acid pre-treated zeolite $\mathrm{NaY}$, are shown. The $\mathrm{pH}$ in the medium, using pre-treated zeolite, was maintained around 3. As it was expected, the iron adsorption of pre-treated zeolite was lower; however this fact permits to assure that the iron is entrapped in the zeolite structure and not precipitated on the surface. 


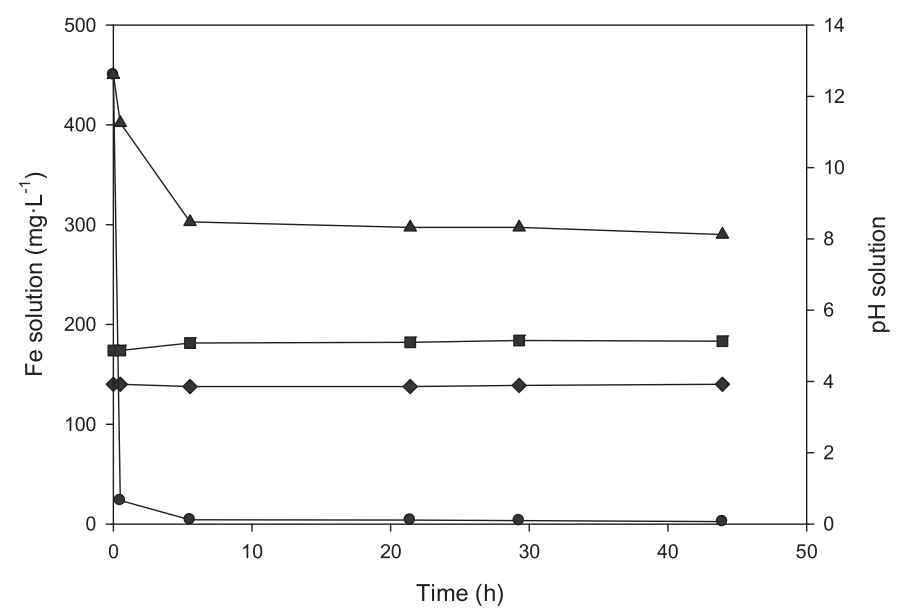

Fig. 2. Adsorption tests using untreated zeolite (filled circles Fe solution; filled squares $\mathrm{pH}$ ) and acid-pretreated zeolite (filled triangles Fe solution; filled diamonds $\mathrm{pH})$ at an initial iron concentration in solution of $500 \mathrm{mg} \mathrm{L}^{-1}$.

Acid pre-treated zeolite maintained the $\mathrm{pH}$ in the solution at a value around 3, which leaded to a lower and slower iron adsorption because none precipitation over the clay structure is produced.

After that, the kinetic study was performed with the acid pretreated zeolite NaY. This study permits to determine the equilibrium time and reaction order of the studied system. Pseudo-first and pseudo-second-order models were evaluated to find the best fitted model for the experimental obtained data. From the obtained data can be stated that 60 minutes is the necessary time to reach the equilibrium. Based on the correlation coefficients $\left(R^{2}\right)$ obtained for both models, it was determined that the behaviour of the $\mathrm{Fe}(\mathrm{III})$ adsorption into pre-treated zeolite followed a kinetic of pseudosecond-order (Fig. 3) following the equation:

$t / q_{t}=1 /\left(q_{e}^{2} \cdot k_{2}\right)+t / q_{e}$

where $q_{t}\left(\mathrm{mg} \mathrm{g}^{-1}\right)$ is the iron uptake at time $t(\min ), q_{e}$ is the iron uptake at equilibrium and $k_{2}$ the second-order $\left(\mathrm{g} \cdot(\mathrm{mg} \cdot \mathrm{min})^{-1}\right)$ equilibrium rate constant. This pseudo-second-order kinetic is in accordance with the findings of others authors using high specific surface clays as kaolinite or sepiolite [17,31].

Adsorption isotherms are characterized by constant values, which express the surface properties and affinity of the adsorbent

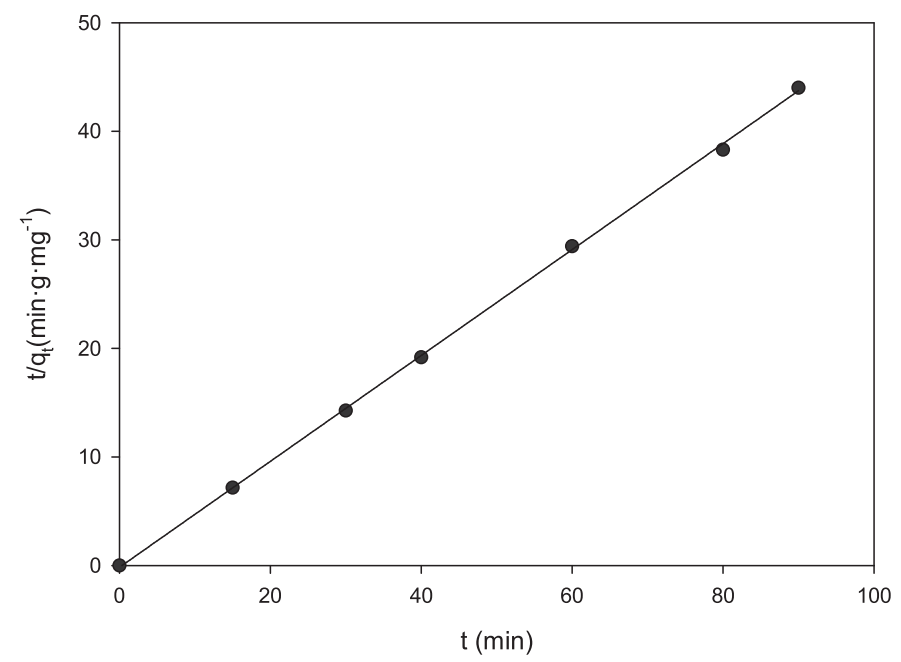

Fig. 3. Adsorption kinetic of Fe-Y: filled circles indicate experimental data and the line indicates the adjustment to a pseudo-second-order kinetic equation ( $t$ / $\left.\mathrm{q}_{\mathrm{t}}=7.89 \mathrm{e}-10+0.4845 \mathrm{t} ; \mathrm{R}^{2}=0.9996\right)$.

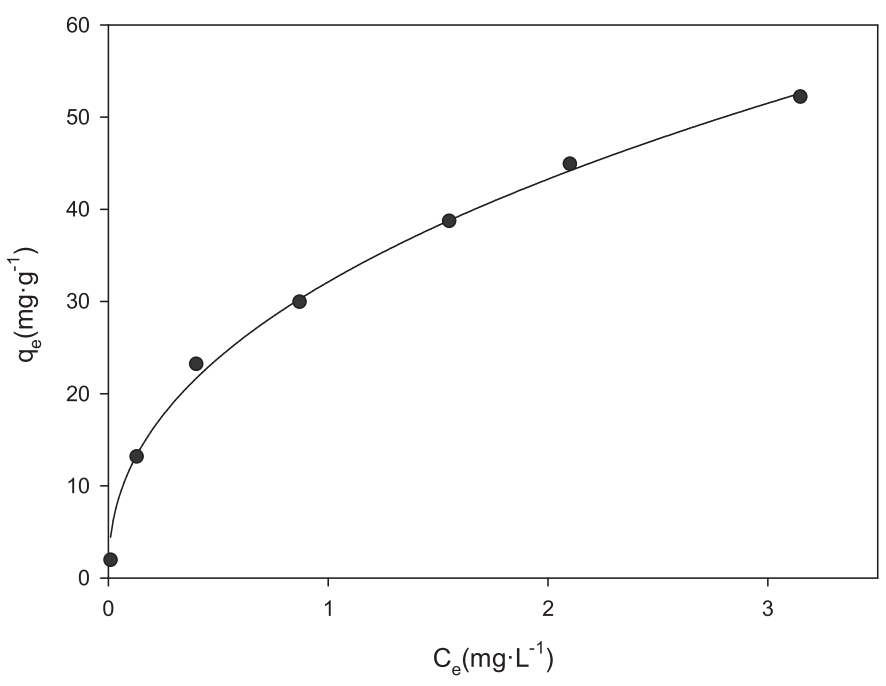

Fig. 4. Isothermal adsorption of Fe-Y: filled circles indicate experimental data and the line indicates the simulated Freundlich model $\left(\mathrm{q}_{\mathrm{e}}=32.12 \cdot \mathrm{C}_{\mathrm{e}}{ }^{0.43} ; \mathrm{R}^{2}=0.9946\right)$.

[32]. Therefore, adsorption isotherms assays with the pretreated clay were carried out to determine the adsorbed mass of iron per mass of $\mathrm{Y}$ zeolite for Fe (III) concentrations ranging from 50 to $1000 \mathrm{mg} \mathrm{L}^{-1}$.

Langmuir, Henry and Freundlich isotherms were used to evaluate the experimental data. The evaluations of these models were carried out and the best model was established by the comparison of the correlation coefficients. From the studied isotherms, Freundlich fitted well to the experimental data (Fig. 4) suggesting that a physical adsorption took place. The Freundlich isotherm can be represented as the following equation:

$\mathrm{q}_{\mathrm{e}}=k_{\mathrm{F}} C_{e}^{\frac{1}{n}}$

where $\mathrm{k}_{\mathrm{F}}\left(\mathrm{mg}^{1-1 / \mathrm{n}} \cdot \mathrm{L}^{1 / \mathrm{n}} \cdot \mathrm{g}^{-1}\right)$ is the Freundlich constant and $n$ is a constant that characterizes the affinity between the sorbent and the solute. It is generally stated that values of $n$ in the range 110 represent good adsorption and less than 1 poor adsorption characteristics. In the present study, $n$ value was 2.3 meaning that the physical adsorption of Fe onto sepiolite has a high affinity [33].

\section{$\mathrm{Fe}-\mathrm{Y}$ characterization}

The Fe-Y obtained in the adsorption assays was characterized using FTIR and SEM analysis in order to determine the presence and distribution of Fe.

The FT-IR spectra show the characteristic signs of zeolite NaY with well-defined signals in the $450-1200 \mathrm{~cm}^{-1}$ [34]. The signal appearing in the region of $1000-1100 \mathrm{~cm}^{-1}$ is attributable to the extensions of asymmetric vibrations of the units $(\mathrm{Si} / \mathrm{Al}) \mathrm{O}_{4}[34]$ and the asymmetric extensions of the chains $\mathrm{Al}-\mathrm{O}-\mathrm{Si}$ in the zeolite can be clearly identified at the $1025 \mathrm{~cm}^{-1}$ signal [35]. The signal appearing at about $1635 \mathrm{~cm}^{-1}$ is due to lattice water molecules and the signal of $3425 \mathrm{~cm}^{-1}$ is characteristic of the surface hydroxyl groups $[34,35]$. NaY zeolite shows characteristic bands at 578 and $791 \mathrm{~cm}^{-1}$, associated with external connections between tetrahedra, which are sensitive to the entire structure. These bands are displaced slightly to lower wavenumbers when iron is present in the zeolite because the $\mathrm{Fe}-\mathrm{O}$ bonds are longer than the $\mathrm{Si}-\mathrm{O}$ bonds [36], therefore it seems that the presence of Fe in the zeolite results in a slight modification of the IR spectrum. Although the characteristic band at $686 \mathrm{~cm}^{-1}$ associated with the Si-O- bonds Fe [36] did not appear. 
Table 2

EDS compositional output of spectrum of zeolite and Fe-Y with normalized abundances.

\begin{tabular}{lllll}
\hline Element & $\begin{array}{l}\text { Y Zeolite } \\
\text { Weight (\%) }\end{array}$ & Atomic (\%) & $\begin{array}{l}\text { Fe-Y } \\
\text { Weight (\%) }\end{array}$ & Atomic (\%) \\
\hline OK & 47.66 & 60.87 & 53.90 & 68.21 \\
NaK & 4.26 & 3.79 & 1.87 & 1.65 \\
AIK & 11.97 & 9.07 & 8.31 & 6.24 \\
SiK & 36.11 & 26.27 & 29.61 & 21.34 \\
SK & - & - & 1.04 & 0.66 \\
FeK & - & - & 5.26 & 1.91 \\
\hline
\end{tabular}

ABBREVIATIONS Fe-Y, iron supported Y zeolite; Al-Fe-Y, iron supported Y zeolite embedded in alginate gel.

Therefore, to evaluate the distribution of iron in the Fe-Y, SEM/ EDS images were performed. From these analyses the presence of iron in the supported zeolite (5.26\% weight (Table 2$)$ ) and the homogeneous distribution can be clearly appreciated.

\section{Electro-Fenton treatment of pesticides using $\mathrm{Fe}-\mathrm{Y}$}

Initially, the electro-Fenton treatment of a solution of the neonicotinoid pesticide imidacloprid $\left(100 \mathrm{mg} \mathrm{L}^{-1}\right)$ was treated using the heterogeneous catalyst Fe-Y. Several concentrations of iron were tested ( $700 \mathrm{mg} \mathrm{L}^{-1}, 350 \mathrm{mg} \mathrm{L}^{-1}$ and $50 \mathrm{mg} \mathrm{L}^{-1}$ ) in order to evaluate the influence of the catalyst concentration. For this purpose, the necessary amount of Fe-Y with an iron content of $52.21 \mathrm{mg} \mathrm{g}^{-1}$ was placed in the $0.15 \mathrm{~L}$ cylindrical electro-Fenton cell and an electric field of $5 \mathrm{~V}$ was applied [26]. It is well known that in the electro-Fenton reaction the $\mathrm{pH}$ plays an important role because the catalyst inactivation is produced at $\mathrm{pH}$ values higher than 4, reducing the efficiency of the treatment [37]. However, in this study the $\mathrm{pH}$ in the reaction mixture was not controlled during the experiments because it decreased from 6 to 3 by the action of acid-pretreated catalyst. This fact presents a great advantage because the developed catalyst permits the application of the treatment without $\mathrm{pH}$ adjustment and favors the degradation rate.

In Fig. 5, the degradation profiles of imidacloprid using different amounts of catalyst in solution are shown. The highest concentration of iron in solution produces a slight increase on the degradation rate; however, after 120 minutes the removals reached for all tested iron concentrations were around 98\%. Dealing with energy consumption, $50 \mathrm{mg} \mathrm{L}^{-1}$ and $350 \mathrm{mg} \mathrm{L}^{-1}$ of iron concentration

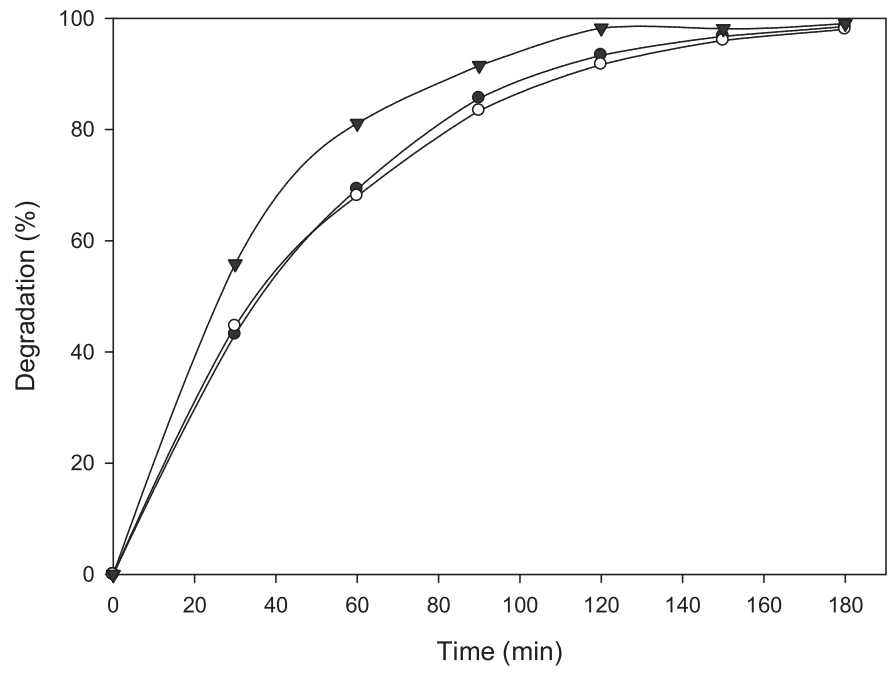

Fig. 5. Degradation profiles of imidacloprid using the heterogeneous electro-Fenton with Fe-Y at different concentrations of iron: $50 \mathrm{mg} \mathrm{L}^{-1}$ (filled circles), $350 \mathrm{mg} \mathrm{L}^{-1}$ (white circles), $700 \mathrm{mg} \mathrm{L}^{-1}$ (filled triangles).

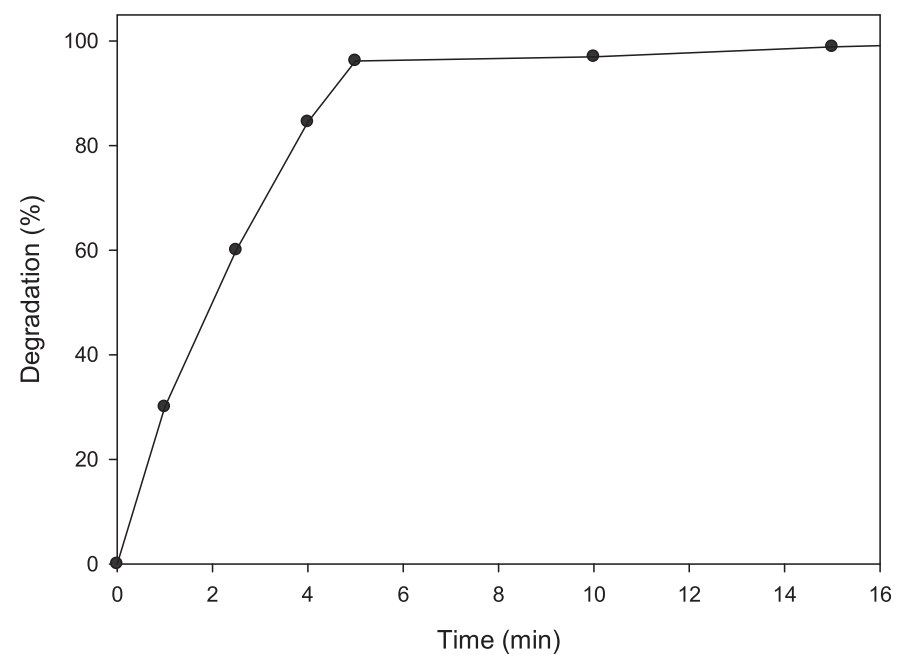

Fig. 6. Degradation profile of chlorpyrifos using the heterogeneous electro-Fenton with Fe-Y with an iron concentration of $50 \mathrm{mg} \mathrm{L}^{-1}$.

require 8.1 and $8.2 \mathrm{kWh} \cdot \mathrm{kg}_{\text {pesticide }}{ }^{-1}$ respectively, while $700 \mathrm{mg} \mathrm{L}^{-1}$ of iron requires $11.2 \mathrm{~kW} \mathrm{~h} \cdot \mathrm{kg}_{\text {pesticide }}{ }^{-1}$. According with previous studies [38] the degradation rate was limited by the $\mathrm{H}_{2} \mathrm{O}_{2}$ production due to the applied voltage. Therefore this fact was the limiting factor instead of catalyst concentration.

Analysis of imidacloprid degradation compounds were performed using HPLC-MS. As it was predictable, a similar degradation pathway (5-hydroxy derivative and 6-chloronicotinic acid) than our previous study [26] was found, when the imidacloprid molecule was mineralized by the electro-Fenton process using iron alginate beads.

The kinetic behaviour of the system was studied and the concentration data through the time were adjusted to several kinetic models. For all catalyst concentrations, the reduction of pollutant concentration fitted well with the pseudo-first-order kinetic expression $\left(R^{2} 0.99\right)$ during initial treatment times. This fact is in accordance with the results reported by Kaichouh et al. [39] in the degradation of herbicides imazapyr and imazaquin by hydroxyl radicals generated in electro-Fenton process.

After that, the heterogeneous electro-Fenton treatment of low solubility pesticide, chlorpyrifos was carried out. This pesticide is an organophosphate insecticide that acts on the nervous system of insects by inhibiting acetylcholinesterase. Based on the previous results, the treatment was carried out using the lowest iron concentration of $50 \mathrm{mg} \mathrm{L}^{-1}$. As it can be observed in the degradation profile (Fig. 6), even though after 5 minutes, 96\% of degradation was reached; it hinders the study of degradation intermediates. Due to the low concentration of chlorpyrifos, that can be found in groundwater systems, the experiments were carried out at a concentration $1.3 \mathrm{mg} \mathrm{L}^{-1}$, which is quickly removed by means of this new heterogeneous process while the energy cost is much higher than for imidacloprid degradation $\left(264.9 \mathrm{~kW} \mathrm{~h} \cdot \mathrm{kg}_{\text {pesticide }}{ }^{-1}\right)$. In this case typical intermediate products [40], such as 3,5,6-trichloro-2pyridinol or dieyhylthiophosphate, were not detected in the HPLCMS. This can be attributed to the high kinetic removal of this pesticide and the low concentration. Similarly to the kinetic analysis of imidacloprid degradation, a high regression coefficient $\left(R^{2} 0.99\right)$, was obtained when the chlorpyrifos concentration decay was fitted to a pseudo-first-order kinetic expression during initial treatment times.

As zeolite has a well known adsortive properties [20,21], the pesticide retained onto zeolite after the electro-Fenton treatment was analysed by mixing $1 \mathrm{~g}$ of dried zeolite with $10 \mathrm{~mL}$ of acetonitrile for 120 minutes. Results showed that after treatment 


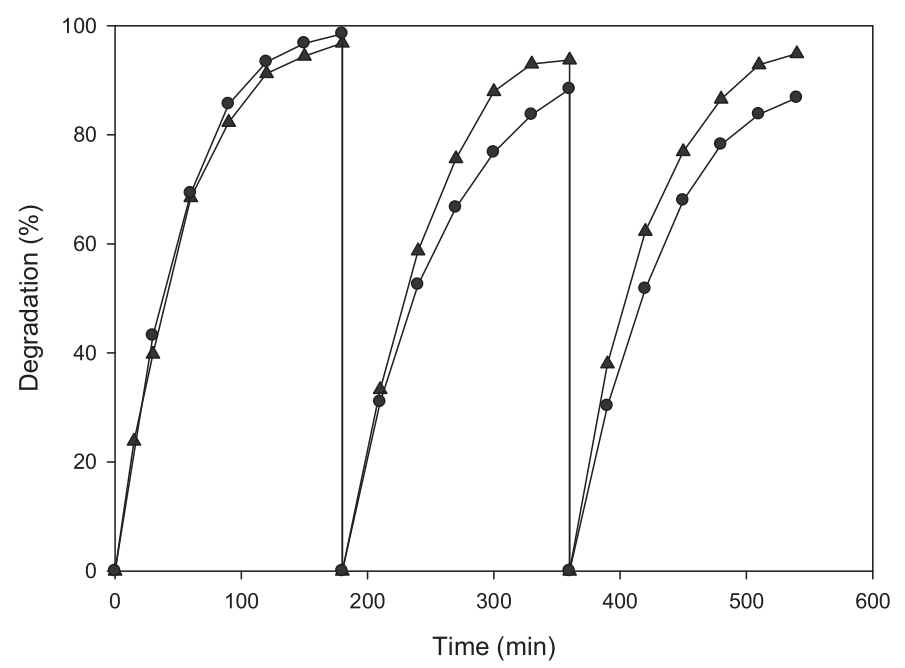

Fig. 7. Degradation profile of imidacloprid using the heterogeneous electro-Fenton process when $\mathrm{Fe}-\mathrm{Y}$ ( filled circles) and $\mathrm{Al}-\mathrm{Fe}-\mathrm{Y}$ (filled triangles) are recycled with an iron concentration of $50 \mathrm{mg} \mathrm{L}^{-1}$.

there was not pesticide adsorbed on the zeolite. Therefore the reduction on pesticides concentration was due to its degradation through electro-Fenton reactions.

\section{Fe-Y Recyclability}

To analyze the applicability of the developed catalyst to operate in successive cycles, several electro-Fenton treatments were carried out in a feed-back process. With the object of reducing the operational cost and taking into account the slight differences between the degradation levels reached using different amounts of catalyst, the iron concentration selected for these studies was the lowest, $50 \mathrm{mg} \mathrm{L}^{-1}$. The electro-Fenton treatment of the highly soluble pesticide, imidacloprid $\left(100 \mathrm{mg} \mathrm{L}^{-1}\right)$, was carried out and the degradations obtained after first, second and third cycle were, $98 \%, 88 \%$ and $86 \%$, respectively and energy consumption was 8.1 , 13.5 and $12.2 \mathrm{~kW} \mathrm{~h} \cdot \mathrm{kg}_{\text {pesticide }}{ }^{-1}$ respectively (Fig. 7). These results confirm that the catalytic activity of the Fe-Y was slightly reduced and the energy consumption slightly increased. Iron leaching was measured during the assays and negligible metal concentration was determined in the liquid supernatant. To analyze the reduction of the catalyst activity, the reaction mixture liquid was filtrated and the amount of catalyst was weighted after third cycle. It was found that a loss of weight around $8 \%$ of catalyst. This fact was attributed to the loss of Fe-Y between each batch as a result of its physical appearance as powder. Therefore, it was postulated that an improvement of physical properties of the catalyst should be done.

\section{Electro-Fenton treatment of pesticide using $\mathrm{Al}-\mathrm{Fe}-\mathrm{Y}$}

\section{Catalyst characterization}

Our previous studies $[11,16,26]$ have determined that the entrapment of iron in hydrogels increases the efficiency of the electro-Fenton processes operating in continuous mode, however the physical resistance of the alginate beads was reduced after several batches and iron leaching occurred. Recently, Dogan [41] and Ghadiri at al. [42] have demonstrated that the combination of clay mineral with alginate improves alginate mechanical characteristics and adsorption properties. Therefore in this study a hybrid biocomposite made of alginate and Fe-Y was developed.

For this aim, the Fe-Y, developed in the aforementioned studies, was entrapped in Ca-alginate. It is well known that Na-alginate solution rapidly gelled upon contact with divalent cations $\left(\mathrm{Ca}^{2+}\right)$ and carboxyl groups of the alginate polymer chains. By using this characteristic, composite beads Al-Fe-Y were prepared. For the practical application, bead particles have advantages in terms of applicability to a wide variety of process configurations in terms of reusability for repeated runs and recovery. The physical characterization of the new catalyst was performed using SEM/EDS microscopy (Fig. 8). The polymeric beads show similar surface morphology and spherical shape than those reported by Shawky [43] where alginate/montmorillonite composite beads were developed. The presence and homogenous distribution of $\mathrm{Fe}$ in the beads was confirmed by EDS mapping analysis (Fig. 8), where white points represent the presence of iron, and which corresponds with the zeolite that can be observed on SEM image.

\section{Electro-Fenton treatment of imidacloprid with Al-Fe-Y}

With the intention of testing the new developed catalyst, the electro-Fenton treatment of the imidacloprid pesticide (100 $\mathrm{m} \mathrm{L} \mathrm{L}^{-1}$ ) was carried out for analyzing the degradation process. The treatment was accomplished in similar way to the previous studies, using an iron concentration of $50 \mathrm{mg} \mathrm{L}^{-1}$. For this purpose $4.3 \mathrm{~g}$ of alginate beads, containing $0.14 \mathrm{~g}$ of Fe-Y, were used in the reactor.

In Fig. 7 the degradation profile of the electro-Fenton treatment of the studied pesticide using the developed catalyst $\mathrm{Al}-\mathrm{Fe}-\mathrm{Y}$ is shown. The results were elucidated comparing the imidacloprid degradation profile using Fe-Y with a final concentration of iron in the reaction mixture of $50 \mathrm{mg} \mathrm{L}^{-1}$. As it can be seen, similar degradation profiles were obtained; therefore the entrapment did not modify Fe-Y activity. The previous studies have demonstrated that the reusability of the catalyst is a key factor in the development of heterogeneous electro-Fenton treatment. Therefore, several cycles were accomplished using the same Al-Fe-Y beads (Fig. 7). The catalyst activity showed similar performance in the different cycles reaching a removal higher than 93\% in all cases. Furthermore, energy consumption was $10.8,11.3$ and $10.6 \mathrm{~kW} \mathrm{~h} \cdot \mathrm{kg}_{\text {pesticide }}{ }^{-1}$ for
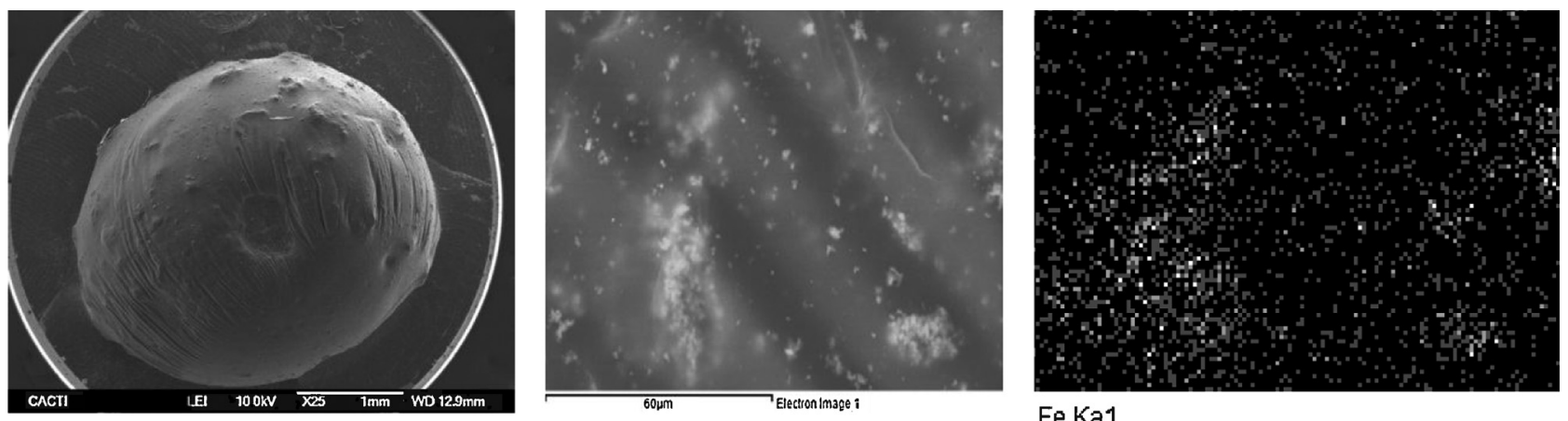

Fe Ka1

Fig. 8. SEM images of surface morphology of Al-Fe-Y (left and centre) and EDS mapping of Al-Fe-Y (right). 
first, second and third cycle respectively. The study of pesticide adsorption at the studied conditions on Al-Fe-Y beads showed that an adsorption lower than $5 \%$ is attained when beads are in contact for more than 60 minutes as postulated Rosales et al. [11] for dye adsorption on alginate beads. Therefore, it was demonstrated that this new catalyst Al-Fe-Y shows a stable background of catalytic activity for the electro-Fenton treatment of pesticide polluted groundwater.

\section{Conclusions}

The reported experimental studies demonstrated that heterogeneous catalysts using Al-Fe-Y could be efficiently used to remove commonly applied pesticides, imidacloprid and chlorpyrifos, from aqueous medium. The short-time of treatment, necessary to degrade the pollutants, opens a promising way to the developed electro-Fenton technology using heterogeneous catalysts, as a new alternative to be coupled with the P\&T process for groundwater remediation. No intermediate products were detected at the end of the treatment; therefore a completed mineralization can be achieved. Accordingly, the process developed in this work can be postulated as an environmental friendly treatment.

\section{Acknowledgements}

This work has been supported by the Xunta de Galicia (EM2012/ 083). The authors are thankful to the Ramón y Cajal programme for Marta Pazos' financial support and to C.A.C.T.I. from Vigo University for providing access to their Electron Microscopy Service.

\section{References}

[1] R.M. Cohen, J.W. Mercer, R.M. Greenwald, M.S. Beljin, USEPA 540 (1997).

[2] M. Köck-Schulmeyer, A. Ginebreda, C. Postigo, T. Garrido, J. Fraile, M. López de Alda, D. Barceló, Sci. Total Environ. 470-471 (2014) 1087-1098.

[3] M. Neumann, R. Schulz, K. Schäfer, W. Müller, W. Mannheller, M. Liess, Water Res. 36 (2002) 835-842.

[4] O. Primo, A. Rueda, M.J. Rivero, I. Ortiz, Ind. Eng. Chem. Res. 47 (2008) 946-952.

[5] A.C. Affam, M. Chaudhuri, J. Environ. Manage. 130 (2013) 160-165.

[6] M.J. Hedegaard, H.-. Albrechtsen, Water Res, 48 (2014) 71-81.

[7] N.W. Brown, E.P.L. Roberts, Water Sci. Technol. 68 (2013) 1216-1222.

[8] J.R. Domínguez, T. González, P. Palo, E.M. Cuerda-Correa, Ind. Eng. Chem. Res. 51 (2012) 2531-2538.

[9] A. Santos, P. Yustos, S. Rodriguez, E. Simon, A. Romero, Ind. Eng. Chem. Res. 49 (2010) 5583-5587.
[10] P.V. Nidheesh, R. Gandhimathi, Desalination 299 (2012) 1-15.

[11] E. Rosales, O. Iglesias, M. Pazos, M.A. Sanromán, J. Hazard. Mater. 213-214 (2012) 369-377.

[12] Y. Wang, H. Zhao, M. Li, J. Fan, G. Zhao, Appl. Catal. B Environ. 147 (2014) 534-545

[13] Y. Wang, H. Zhao, G. Zhao, Y. Wang, X. Yang, Progr. Chem. 25 (2013) 1246-1259.

[14] Y.-. Lee, S.-. Chang, M.-. Choi, T.-. Jeon, T. Ryu, Y.S. Huh, Appl. Catal. B Environ. 142 143 (2013) 494-503.

[15] C.-. Cao, L.-. Meng, Y.-. Zhao, Toxicol. Environ. Chem. 95 (2013) 747-756.

[16] O. Iglesias, E. Rosales, M. Pazos, M.A. Sanromán, Environ. Sci. Pollut. Res. 20 (2013) 2252-2261.

[17] O. Iglesias, M.A. Fernández de Dios, M. Pazos, M.A. Sanromán, Environ. Sci. Pollut. Res. 20 (2013) 5983-5993.

[18] Q. Wang, S. Tian, P. Ning, Ind. Eng. Chem. Res. 53 (2014) 643-649.

[19] M.A.F. de Dios, O. Iglesias, E. Bocos, M. Pazos, M.A. Sanromán, J. Ind. Eng. Chem. 20 (2014) 3754-3760.

[20] S. Malamis, E. Katsou, J. Hazard. Mater. 252-253 (2013) 428-461.

[21] M.A. Shavandi, Z. Haddadian, M.H.S. Ismail, N. Abdullah, Z.Z. Abidin, J. Taiwan Inst. Chem. Eng. 43 (2012) 750-759.

[22] S. Fukuchi, R. Nishimoto, M. Fukushima, Q. Zhu, Appl. Catal. B Environ. 147 (2014) 411-419.

[23] I. Kiran, N. Bektas, H. Cengiz Yatmaz, M. Tekbas, Desalin. Water Treat. 51 (2013) $5768-5775$.

[24] K.S. Walton, M.B. Abney, M.D. LeVan, Microporous Mesoporous Mater. 91 (2006) $78-84$.

[25] M. Pazos, M. Branco, I.C. Neves, M.A. Sanromán, T. Tavares, Chem. Eng. Technol. 33 (2010) 2008-2014

[26] O. Iglesias, J. Gómez, M. Pazos, M.A. Sanromán, Appl. Catal. B Environ. 144 (2013) 416-424.

[27] S.A. Abdel-Gawad, A.M. Baraka, K.A. Omran, M.M. Mokhtar, Int. J. Electrochem. Sci. 7 (2012) 6654-6665

[28] M. Lamers, M. Anyusheva, N. La, V.V. Nguyen, T. Streck, Clean Soil Air Water 39 (2011) 356-361.

[29] S. Sánchez-González, E. Pose-Juan, E. Herrero-Hernández, A. Álvarez-Martín, M.J. Sánchez-Martín, S. Rodríguez-Cruz, Int. J. Environ. Anal. Chem. (2013).

[30] L.A. Oste, T.M. Lexmond, W.H. Van Riemsdijk, J. Environ. Qual. 31 (2002) 813-821.

[31] S. Shahmohammadi-Kalalagh, H. Babazadeh, A.H. Nazemi, M. Manshouri, Caspian J. Env. Sci. 9 (2011) 243-255.

[32] K.M. Al-Qahtani, World Appl. Sci. J. 16 (2012) 465-473.

[33] A.S. Özcan, B. Erdem, A. Özcan, Colloids Surf. A Physicochem. Eng. Asp. 266 (2005) 73-81.

[34] K.K. Bania, R.C. Deka, J. Phys. Chem. C. 116 (2012) 14295-14310.

[35] I. Kuzniarska-Biernacka, A.M. Fonseca, I.C. Neves, Inorg. Chim. Acta 394 (2013) 591-597.

[36] M.M. Mohamed, N.A. Eissa, Mater. Res. Bull. 38 (2003) 1993-2007.

[37] E. Rosales, M.A. Sanromán, M. Pazos, Environ. Sci. Pollut. Res. 19 (2012) 1738 1746.

[38] M. Skoumal, C. Arias, P.L. Cabot, F. Centellas, J.A. Garrido, R.M. Rodríguez, E. Brillas, Chemosphere 71 (2008) 1718-1729.

[39] G. Kaichouh, N. Oturan, M.A. Oturan, A. El Hourch, K. El Kacemi, Environ. Technol. 29 (2008) 489-496.

[40] F. Moscoso, I. Teijiz, F.J. Deive, M.A. Sanromán, Bioprocess Biosyst. Eng. 36 (2013) 1303-1309.

[41] H. Dogan, Toxicol. Environ. Chem. 94 (2012) 482-499.

[42] M. Ghadiri, W. Chrzanowski, W.H. Lee, A. Fathi, F. Dehghani, R. Rohanizadeh, Appl. Clay. Sci. 85 (2013) 64-73.

[43] H.A. Shawky, J. Appl. Polym. Sci. 119 (2011) 2371-2378. 